Public and private in Hegel's philosophy. The splittings of modern word

\title{
Lo público y lo privado en la filosofía de Hegel. Las escisiones del mundo moderno
}

\author{
Alba Baro Vaquero \\ Estudiante de doctorado en la Universidad Autónoma de Madrid \\ alba.barovaquero@gmail.com \\ DOI: https://doi.org/10.15366/bp.2020.24.011 \\ Bajo Palabra. II Época. № 24. Pgs: 213-228
}

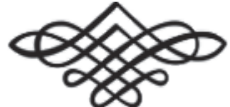


Recibido: 06/11/2018

Aprobado: 28/07/2020

\section{Resumen}

El artículo explora la relación entre lo público y lo privado en el mundo moderno tal como queda comprendida en la filosofía del Hegel maduro, fundamentalmente en su Filosofía del Derecho. El propósito es dar cuenta de la centralidad de estas dos categorías en la comprensión hegeliana sobre la conformación del Estado en la modernidad y el movimiento dialéctico de la Historia. Frente a la etapa de juventud, el filósofo alemán acaba aceptando la irrenunciabiliad del principio de particularidad y de la propiedad privada .Si bien, la aparición de la sociedad civil, como nueva esfera intermedia, dedicada a los intereses económicos, plantea serios obstáculos que el sistema hegeliano no parece capaz de integrar.

Palabras clave: Hegel, público/privado, sociedad civil, modernidad.

\section{Abstract}

This article explores the relationship between public and private in Modern World as it is understood by Hegel in his later philosophy, especially in the Phylosophy of Right. The purpose is to account for the centrality of these two categories in the Hegelian understanding about the conformation of the modern State and the dialectical movement of the History. As opposed to his early period, the german philosopher accepted that the particularity principle and private property were not renounceable. However, the emergence of civil society, as a new intermediate sphere, presents serious obstacles that the hegelian system doesn't seems to be able to integrate.

Keywords: Hegel, public/private, civil society, modern age. 


\section{Introducción}

LA RELACIÓN ENTRE LO PÚBLICO Y LO PRIVADO constituye una dicotomía central en la ordenación socio-política de la modernidad. En su esfuerzo por hacer de la filosofía la "captación de lo presente y lo real" para elevarlo a concepto, el planteamiento de Hegel sobre lo público y lo privado toma un cariz nuevo con respecto a sus predecesores en la teoría política, fundamental para comprender las transformaciones que estaban sufriendo las sociedades europeas y que aun definen nuestro presente. El artículo pretende hacer un recorrido, a través de este par conceptual, por las tres etapas de la eticidad (familia, sociedad civil y Estado) que conforman el mundo moderno, tal como quedan comprendidas en el Hegel maduro y, más en concreto, en su Filosofía del Derecho. En la etapa tardía a la que corresponde dicha obra, el filósofo ya ha dejado atrás sus esperanzas de recuperar la viva esfera pública griega y el entusiasmo juvenil por la Revolución francesa, aceptando el principio de particularidad y la propiedad privada como momentos negativos y necesarios del devenir histórico y de la conformación del Estado moderno. Ello no supone, por tanto, abandonar la crítica a la privatización de la existencia, cuyo punto álgido se habría alcanzado en el Imperio romano, pero sí conlleva una revalorización del aporte de la religión cristiana, de modo que la Reforma pasa a cobrar también un papel clave en el amanecer del nuevo mundo. Si bien, más allá de estas cuestiones, lo que la lectura de Hegel centrada en las categorías de lo público y lo privado nos permite poner en primer plano son los problemas y dificultades que la emergencia de la sociedad civil (como esfera intermedia, fruto de la expansión de la economía de mercado, regida por los intereses privados y generadora de desigualdades) plantea dentro del sistema hegeliano y para la realización de la libertad en el nuevo espacio público.

\section{La familia}

LA FAMILIA ES LA ETICIDAD en la forma de lo natural ${ }^{1}$. La base de su unidad es, no la razón, como ocurrirá con el Estado, sino un sentimiento: el "amor ético" 2 . El in-

\footnotetext{
${ }^{1}$ Cf., Hegel, G.W.F., Lineas fundamentales de la Filosofía del Derecho, Madrid, Gredos, 2010, parágrafo 158.

2 Como apunta Barroso, este amor ético (un amor consciente, que ha salido de la inmediatez del instinto y del sí mismo y que implica, por tanto, autolimitación), le servirá a Hegel para explicar la unión con el Estado y el
} 
dividuo dentro de ella aun se define primeramente por ser miembro del todo y solo en tanto que tal, en función de lo que es para el otro, llega a lograr autoconciencia de la propia individualidad.

A través del tiempo cíclico de las generaciones, se transmiten, en el seno de la vida familiar, las tradiciones y la memoria ${ }^{3}$. Es a la mujer a la que corresponde dicha tarea, tal como se encuentra representada en la figura de Antígona: su disposición de ánimo propia es la piedad, en ella rige la ley eterna de "dioses subterráneos", "de la interioridad que aun no ha alcanzado su realización perfecta", en contraposición a ley de la virilidad y del Estado ${ }^{4}$. La mujer tiene, pues, para Hegel, su determinación sustancial en el ámbito privado de la vida familiar. Solo al hombre corresponde salir a la vida exterior y pública.

Pero, aunque presente la Antigüedad, la familia no es una institución atemporal. En la Filosofía del Derecho la forma de familia de la que nos habla Hegel es la específica del mundo moderno. Es decir, se haya penetrada ya por el principio de amor cristiano y por la Reforma (gracias a la cual el cristianismo ha podido reconciliarse con lo exterior y temporal, en el caso de la familia, a través de la abolición del voto de castidad católico). Así, frente a la familia antigua, esta se funda ahora en el libre consentimiento. La casa es la esfera donde se desarrollan las relaciones de confianza y seguridad, contrapunto de la soledad y movilidad a las cuales el hombre adulto habrá de hacer frente en la sociedad civil.

Tras el matrimonio, la familia toma su realidad externa en la propiedad y el cuidado de sus bienes, como un "patrimonio compartido" 5 . Su tercer momento es la educación, a través de la cual los padres ofrecen a los hijos un mundo ya penetrado por la forma de la conciencia, para culminar así con la disolución de la misma familia, una vez estos se emancipan.

\section{La sociedad civil}

El LUgar al QUe arRIBa ese hijo recién emancipado de la casa familiar es la ciudad. Pero tampoco esta, en la época moderna, tiene ya nada que ver con la

efecto liberador de las exigencias y constricciones que en apariencia este impone (Barroso, Óscar, "La familia como momento de la esfera de la eticidad”, El Búho, 2008, pp.89-97).

3 Cf. Duque, F., Historia de la filosofía moderna: la era crítica, Madrid, Akal, 1998, p.822; Villacañas Berlanga, J.

L., La hegemonía del pensamiento de Hegel, Madrid, Síntesis, 2001., p.47.

4 En la que es nada menos que "la oposición ética suprema" (Hegel, G.W.F., Líneas fundamentales de la Filosofía del Derecho, óp. cit., parágrafo 166).

5 Cf., Ibíd.., parágrafo 170. 


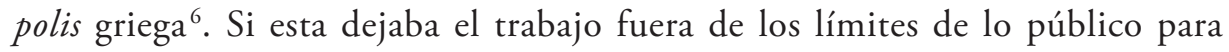
que los ciudadanos pudieran entregarse a la organización y celebración de la misma, nos encontramos ahora con una ciudad cuyo protagonista es el "esta-

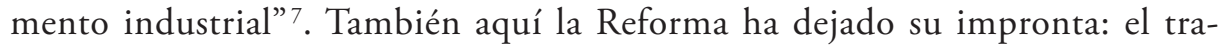
bajo, revalorizado por la abolición del voto cristiano de pobreza ${ }^{8}$, se vuelve el principio fundamental en la organización de la sociedad civil. La sociedad civil constituye un ámbito nuevo, en el cual toma realidad y alcanza su plenitud ese punto de inflexión respecto a la época antigua que supone el principio de particularidad e independencia del individuo (introducido por el cristianismo). De este modo, la salida del ámbito puramente privado ya no implicará entrar directamente en lo público ${ }^{9}$. La vida civil ya no puede seguir identificándose con el Estado: este será "sólo el tercero".

El nuevo emplazamiento del individuo, desprendido de la unidad inmediata de la familia, exige de una situación jurídicamente establecida. Ese estatus jurídico es el de la "persona", base del Derecho Abstracto, cuyo reconocimiento y realización objetiva requiere del respeto de la esfera privacidad constituida por las cosas de las que es propietario. Es decir, que la persona solo es reconocida como tal cuando lo es su derecho a la propiedad, fruto también de la disolución de la familia en la sociedad civil, al disgregarse el patrimonio común. Hegel, que años antes había visto en la propiedad la ruina y disolución del verdadero sentido político del Estado, la ubica ahora en los fundamentos del derecho, comprendiendo que en ella reside nada menos que el destino de mundo moderno ${ }^{10}$.

Trabajo y propiedad privada: el mundo moderno es también el del nacimiento de una nueva ciencia, la economía- política. Trabajo y propiedad permiten al individuo romper con todos sus vínculos inmediatos, "lo que produce y consume ha de agradecerlo principalmente a sí mismo". Por eso Hegel define las ciudades como "sedes de la reflexión que se absorbe en sí y se aísla", lugares donde ha surgido "el sentido de libertad y orden" ${ }^{11}$. En contraste con esta forma de vida independiente, el estamento agrario ve su existencia regida por un sentimiento de dependencia,

${ }^{6}$ La polis griega vivía volcada a la vida pública: "cada ciudadano tenía el derecho y el deber de pronunciar y ejercitar discursos en la plaza pública sobre la administración del Estado, de ejercitarse en los gimnasios y tomar parte en las fiestas" (Hegel, G.W.F., Lecciones de la filosofia de la historia, Madrid, Gredos, 2010, p. 429).

7 El estamento industrial está formado por fabricantes y artesanos. Los otros dos estamentos son los funcionarios ("universal") y el agrario ("sustancial").

${ }^{8}$ Cf. Hegel, G.W.F., Lecciones de la filosofía de la historia, óp. cit., p. 753.

${ }^{9}$ Cf., Ibid., agregado parágrafo 182.

${ }^{10}$ Cf., Zan, J., La filosofia social y politica de Hegel, Buenos Aires, Del Signo, 2009, p. 71. Aunque la personalidad sea la que da derecho a las cosas, como apunta Duque, es solo como propietario de algo que uno deja de ser solo sí mismo, para ser "poseedor, signado por sus propiedades", la "máscara" que representa un papel (Duque, F., Historia de la filosofia moderna: la era critica, óp.cit, p. 811).

${ }^{11}$ Ibid., parágrafo 256. 
que apenas le permite pensar en sí mismo: "todo lo que adquiere es el don de un extraño, la naturaleza", ante el cual ha de "aceptar pacientemente todo lo que pueda sobrevenir" ${ }^{12}$.

En las páginas dedicadas al primer momento de la sociedad civil, el "sistema de las necesidades", nos encontramos con un retrato de las relaciones humanas muy similar a aquel que había ofrecido Hobbes, presentándolo como el de la humanidad en su estado de naturaleza: el carácter propio del estamento industrial se define por el egoísmo, la desmesura y el orgullo de los individuos, cada uno de los cuales es solo un fin para sí mismo. Pero el pensamiento histórico de Hegel le permite comprender que esa esfera, dedicada a los negocios particulares y el ocio, solo corresponde a la "segunda naturaleza" del individuo moderno: allí encuentra este "la experiencia más significativa, [...] más vital, la que mejor toca el núcleo de su ser", mientras "la experiencia pública le parece secundaria, estrecha y provinciana, y no toca más que una parte de sí mismo" ${ }^{13}$.

Si bien, por mucho que se crea hecho a sí mismo, el individuo solo puede satisfacer sus necesidades y alcanzar su singularidad gracias al "trabajo y la satisfacción de la necesidad de todos los demás" ${ }^{14}$. Lejos de vivir encerrado en el estricto ámbito privado, forma parte de un sistema de mutuas dependencias, intermediadas por el mercado y el dinero. Pero el Estado resulta aun un "Estado externo", el terreno de la universalidad aparece todavía únicamente como medio para satisfacer necesidades particulares. Las cuales, impulsadas por el egoísmo y la mano invisible del mercado, van a ir multiplicándose a la vez que los medios para su cumplimiento, alcanzando así, unas y otros, una abstracción cada vez mayor; una profusión de invenciones que da lugar al lujo ${ }^{15}$. Pero el proceso no solo afecta a los productos, el mismo individuo se va "refinando": al estar satisfechas las necesidades fundamentales, el deseo se vuelve menos violento y estas se amplían al ámbito de lo espiritual, donde "lo último que tiene que ser satisfecho no es la necesidad, sino la opinión" ${ }^{16}$.

Con todo ello se sientan las bases para el momento inicial de reconcomiendo mutuo, bajo la forma de una "exigencia de la igualdad con los otros" ${ }^{17}$. De ahí que sea en la sociedad civil, al ser cada cual valorado simplemente por sus contribuciones económicas y cuantitativas, sin atender a cuestiones de estatus, donde va a hacer su aparición "el hombre", ya sin las exclusiones de la polis: "el hombre

\footnotetext{
12 Ibid., agregado parágrafo 204.

13 Taylor, C., Hegel y la sociedad moderna), México D.F., Fondo de cultura económica, 1983, p.178.

${ }^{14}$ Hegel, G.W.F, Lineas fundamentales de la Filosofia del Derecho, óp. cit., parágrafo 188.

15 Ibid., parágrafo 190-195.

16 Cf., Ibid., agregado parágrafo 190.

17 Ibid., parágrafo 193.
} 
vale porque él es hombre, no porque él sea judío, católico, protestante, alemán, italiano, etc." 18 .

Ser "hombre" supone transcender la esfera privada. Pero ahora la universalidad que proporciona la salida a lo público solo "puede adquirir realidad y objetividad ética" a través de la determinación que supone la profesión y la pertenencia un estamento ${ }^{19}$. Profesión que dependerá, según Hegel, de las habilidades y otras circunstancias, pero (y esto es lo "moderno") cuya "última y esencial determinación se encuentra en la opinión subjetiva y en el libre arbitrio particular" ${ }^{20}$.

Ahora bien, el problema del sistema de las necesidades no es solo que su única regulación escape al plano de lo subjetivo, como en el prolífico automatismo de la colmena mandevilliana. En el plano de la realidad, el sistema de necesidades, "es el sistema de la eticidad perdido en sus extremos" 21 . La misma dinámica del mundo, impulsada por la incipiente industriosidad burguesa, genera profundas escisiones que amenazan con destruirla: el ritmo sin trabas de mercado lleva a que se acreciente la acumulación de riquezas, lo cual genera dependencia y penuria de otra parte de la población, favoreciendo con ello una concentración aun mayor de la riqueza en pocas $\operatorname{manos}^{22}$, en un círculo que no deja de retroalimentarse. Junto con las necesidades y los lujos, se multiplican también las desigualdades entre los individuos (más allá de las diferencias entre estamentos).

Claro que, nos encontramos aun en el momento negativo de la eticidad y, por tanto, estas mismas contradicciones terminarán por culminar con su superación y conciliación, en el Estado. Tras el sistema de las necesidades, las mediaciones que se despliegan en la sociedad civil serán ya regulaciones conscientes, que, provenientes del poder público, tratan de corregir las quiebras producidas en la esfera civil: en primer lugar la administración de justicia y, en segundo, la policía y las corporaciones.

La sociedad civil reduce el seguro ámbito familiar a una actividad envolvente, dejando al individuo a la intemperie. Pero la sociedad necesita al individuo tanto como este a aquella, por lo que va a tener que asumir el papel de "familia universal", garantizándole unos derechos que le permitan mantener su independencia y que le exigirán a su vez unos deberes para con ella. Hegel tiene claro, pues, que se requie-

\footnotetext{
${ }_{18}$ Hegel, G.W.F, Lineas fundamentales de la filosofía del derecho, óp. cit., parágrafo 209. La intensa vida pública antigua estaba posibilitada, entre otros factores, por la reclusión de una parte de la población en un ámbito privado dedicado a los trabajos manuales, permitiendo que los demás tuvieran el tiempo y las manos libres para el manejo de la polis.

19 Ibid., parágrafo 207.

${ }^{20}$ Ibid., parágrafo 206.

${ }^{21}$ Ibid., parágrafo 184.

22 Ibid., parágrafo 243
} 
ren, pues, contrapesos a la libertad de industria y comercio (sin amenazar nunca, aclara, el interés subjetivo, definitorio del trabajo moderno). Lo público penetra en lo privado. Así, también, en tanto que "nueva familia", habrá de preocuparse por la educación, no pudiendo dejarla al exclusivo arbitrio de los padres. Por último, tampoco basta con "la vieja institución privada de la caridad" ${ }^{23}$. Esta ayuda depende de la contingencia y corresponder al ámbito de la moralidad, no a una autentica eticidad. "El esfuerzo de la sociedad solo puede dirigirse a atender el problema de la miseria y su solución como algo universal, institucionalizando el remedio" ${ }^{24}$, es decir, a través de mecanismos de asistencia pública.

Sin embargo, estas medidas parecen resultar insuficientes. Observamos que a lo largo de la exposición dedicada a la sociedad civil las escisiones no llegan nunca a quedar del todo resueltas. Se perfila así una contradicción que "la dialéctica hegeliana no sabrá resolver" ${ }^{25}$. De hecho, no es hasta el tercer momento de su desarrollo donde Hegel nos muestra a esta en su rostro más descarnado: un "espectáculo del exceso, de la miseria y de la corrupción física y ética" ${ }^{26}$. Y es también justo en este momento donde introduce un criterio de división social paralela a los estamentos (Stand): una división en "clases" (Klasse), entre los "poseedores de riquezas" y la "plebe", esa gran masa de población que se hunde por debajo del nivel de subsistencia ${ }^{27}$.

Hegel entiende que en el seno mismo de la sociedad civil nace una pobreza genuinamente moderna, que se define, no en términos exclusivamente materiales, sino ante todo por una disposición de ánimo particular. La diferencia respecto a la pobreza debida a las contingencias de la naturaleza es que, ante esta última, "ningún hombre puede sustentar un derecho, pero en situación de sociedad la carencia cobra en seguida la forma de injusticia" ${ }^{28}$. Quienes se ven entregados a las contingencias que imponen las carencias materiales no pueden desarrollar la capacidad de disfrutar de los otros goces y ventajas espirituales de la sociedad civil. De modo que los miembros de la plebe se definen por verse a sí mismos como gentes que carecen (ya no solo de bienes necesarios sino) de derechos que deberían poseer. Surge entonces en ellos una "rebelión interna" contra la riqueza, la sociedad, el gobierno, etc. Hegel encuentra, pues, en la "pobreza moderna" una herida que escinde el mismo espacio público de la ciudad, amenazando con quebrar su anhelado orden.

Las regulaciones provenientes del poder público resultan incapaces de ofrecer soluciones definitivas. Garantizar directamente su subsistencia, sin la mediación

\footnotetext{
23 Ibid., parágrafo 207.

${ }^{24}$ Ibid., parágrafo 242.

25 Cf. Duque, F., Historia de la filosofia moderna: la era crítica, óp.cit, p.827

${ }^{26}$ Hegel, G.W.F, Lineas fundamentales de la filosofía del derecho, óp. cit., parágrafo185

27 Cf., Duque, F., Historia de la filosofía moderna: la era crítica, óp.cit

${ }^{28}$ Hegel, G.W.F, Lineas fundamentales de la filosofía del derecho, óp. cit., parágrafo 244
} 
del trabajo, haría imposible que apareciera sentimiento alguno de independencia y honor (seguirán sin sentirse miembros "espirituales" de la sociedad civil). Mientras que ofrecerles trabajo (así lo impone el círculo macabro de la economía) solo terminaría produciendo nuevos pobres ${ }^{29}$. "Aquí se hace patente que la sociedad civil en medio del exceso de riqueza no es suficientemente rica, es decir, en su propia fortuna no posee suficiente para gobernar el exceso de miseria y el surgimiento de la plebe" ${ }^{30}$.

Llegados a este punto, la única solución que queda es la salida de la sociedad civil hacia el exterior: "por esta dialéctica suya [...] es empujada más allá de sí misma" ${ }^{31}$. Comienza el proceso de colonización, que proporciona nuevos campos de mercado y nuevas tierras a las que migrar, destino fundamentalmente para los miembros de la plebe, quienes no tienen nada dejar atrás.

Podríamos añadir, antes de concluir con este apartado, una última circunstancia propia de la sociedad civil que hace necesaria la intervención del poder público y que, nuevamente, da cuenta de las dificultades, tal vez insalvables, para reconciliar el fuerte empuje de los intereses privados con la recuperación del valor público. Se trata del estamento militar, que el Estado se ve obligado a crear para la defensa y la expansión al exterior, pues, como señala Duque, "la pujante bourgeoise está dispuesta a pagar para que se defiendan sus derechos de clase, incluso infringiendo la muerte, pero no lo está a morir por defender sus privilegios" 32 .

\section{El Estado}

En el Estado culmina el despliegue de la libertad que recorre la Filosofía del Derecho (y la Historita Universal misma). Este es la "primera manifestación de la racionalidad en el mundo", que se cumple tanto en el interior de los ciudadanos, como en el exterior de las instituciones socio-políticas, es decir, tanto en la esfera privada como en la pública. Hegel no se desprenderá nunca de cierta nostalgia por la vida pública griega, pero desde el periodo de Jena, a medida que fue desarrollando su pensamiento, elaborando su método dialéctico ${ }^{33} \mathrm{y}$ comprobando lo peligroso de los proyectos apoyados en la nostalgia, fue abandonando su primera crítica a la sociedad moderna.

\footnotetext{
29 Tampoco cabe una igualdad de propiedad. Una igualdad de este tipo "sería aquí injusticia" (Ibid., agregado parágrafo 49).

30 Ibid., parágrafo 245.

31 Ibid., parágrafo 246.

32 Duque, F., Historia de la filosofía moderna: la era crítica, óp. cit., p.840.

33 Zan, J., La filosofía social y política de Hegel. Trabajo propiedad, óp. cit., p.93
} 
El concepto abstracto y universal de la libertad que el principio de subjetividad trae consigo resulta ya irrenunciable: basta con que "los individuos y los pueblos hayan alcanzado una vez -aunque sea representativamente- el concepto abstracto de la libertad para que éste se imponga irresistiblemente" ${ }^{34}$. Pero, como hemos visto, la valoración negativa de la propiedad y, en general, de lo privado frente a lo público sigue presente. Lo que cambia, como explica De Zan, es la manera en que Hegel trata la función de la negatividad: el término negado no puede ser eliminado, sino conservado dialécticamente y reintegrado en la totalidad ${ }^{35}$. El problema de la propiedad privada frente a lo público no es, por tanto, una cuestión accidental, de utilidad o conveniencia, sino que plantea en el fondo la problemática lógico-metafísica fundamental de la oposición dialéctica entre lo universal y lo particular ${ }^{36}$.

La identificación entre Estado y sociedad, válida en el mundo antiguo, cuando es tomada por los autores modernos, una vez ha aparecido la nueva esfera dedicada al interés particular, implica reducir lo público a una fuerza y garantía externas. Pero como es sabido, el Estado, para Hegel, ya está latiendo ahí, es siempre previo: en tanto que resultado del desarrollo dialéctico es el fundamento concreto de cada una de las premisas ${ }^{37}$. Lo que aporta el momento negativo de los individuos vueltos sobre su vida privada es que su aquiescencia para con el Estado, también toma ahora forma racional, en contraste con la espontaneidad de los ciudadanos de la polis, donde había una identidad inmediata "entre los intereses públicos y los suyos propios" ${ }^{38}$. La Reforma y la "revolución interior" que habría llevado consigo resultan de nuevamente claves en este proceso, pues la abolición las autoridades externas hizo que el hombre hubiera de determinare a sí mismo ${ }^{39}$.

Así que lejos de anularlos, solo el Estado permite el mantenimiento de los intereses particulares y la singularidad personal, su desarrollo pleno y su reconocimiento. A través del derecho, los conserva dentro del interés universal. Por supuesto, ello implica una variación en los mismos intereses del individuo: este no ha de querer al Estado porque le sea útil, sino porque reconoce en él su espíritu sustancial y su mismo fin, en virtud del cual orientar sus acciones. La obligación ante lo sustancial

\footnotetext{
${ }^{34}$ Duque, F., Historia de la filosofía moderna: la era crítica, óp.ci., p. 807

35 Zan, J., La filosofía social y politica de Hegel. Trabajo propiedad, óp. cit. p.93

36 Ibid., p. 95

37 Duque, F., Historia de la filosofía moderna: la era crítica, óp.ci., p.812

${ }^{38}$ Hegel, G.W.F., Lecciones de la filosofía de la historia, óp. cit., p. 576. En el mundo griego, al faltar todavía el elemento hostil que constituyen la reflexión y la voluntad subjetiva, realmente las decisiones eran relegadas a instancias externas: se confió primero en los oráculos y tras el afianzamiento de la democracia, en los criterios desplegados por los oradores.

39 Ginzo Fernández, A., "Política, Religión y Filosofía en G.W.F. Hegel”, Revista de Estudios Políticos, N. 94, 1996, p.142.
} 
y la existencia concreta de su libertad particular, es decir, deber y derecho, quedan identificados ${ }^{40}$.

Tal disposición de ánimo propia del ciudadano es el "patriotismo general" 41 , un reconocimiento basado en la certeza (no en el mero sentir) y acreditado en el curso ordinario de la vida ${ }^{42}$. El patriotismo será mayor cuanto mayor sea "la grandeza del Estado" porque entonces los ciudadanos se implicarán más en los asuntos universales y no se dejarán atrapar en los meramente privados: sean los de la familia y los vínculos personales o las "pasiones privadas" que conducen a la venganza o al odio ${ }^{43}$.

El Estado moderno toma la forma de una monarquía constitucional. Esta, basada en el principio de división de poderes, constituye para Hegel la garantía última de la libertad pública. De este modo, tenemos el momento de particularidad, correspondiente al monarca, el carácter universal, propio del poder legislativo y la subsunción de los casos particulares en lo universal, que lleva a cabo el poder ejecutivo. La unidad que le concede el príncipe hace del Estado un todo orgánico, constituido por miembros que no pueden ser nada de manera independiente. En contraposición, las monarquías feudales no conformaban más que un agregado de corporaciones y comunidades: "eran propiedad privada de individuos" ${ }^{44}$ y por tanto la decisión sobre qué debía ser hecho en relación al todo dependía de su opinión y capricho. Ahora es el príncipe, cúspide donde confluyen los distintos poderes, quien posee el poder de decisión última. La toma de decisiones del Estado, para ser voluntad racional ${ }^{45}$, entiende Hegel, solo puede pertenecer a una instancia única, en tanto que voluntad humana autoconsciente y libre. Si se depositara en la voluntad del pueblo, la vida política quedaría sostenida sobre la base de la abstracta individualidad y entregada a lo accidental de la opinión y el libre arbitrio. "La razón es el fruto del profundo conocimiento e intelección que justamente no es cosa del pueblo" 46 .

Como decíamos, la evolución y elaboración del método dialéctico, le lleva a Hegel a revalorizar lo particular y, en consecuencia, a poner en primer plano la cuestión de las mediaciones ${ }^{47}$. La unidad entre lo universal y lo particular nunca puede ser inmediata. No es posible esperar un equilibrio espontáneo entre lo público y lo privado. La división de poderes, así como la existencia del funcionariado (el "estamento universal") y de las corporaciones permiten que los intereses privados (tanto del lado de los

\footnotetext{
${ }^{40}$ Hegel, G.W.F., Lineas fundamentales de la Filosofía del Derecho, óp. cit., parágrafo 158, .261

${ }^{41}$ Ibid., parágrafo 289.

42 Cf., Ibid., parágrafo 268.

43 Ibid., parágrafo 296.

44 Ibid., parágrafo 279.

45 Cf., Villacañas Berlanga, J. L., La hegemonía del pensamiento de Hegel, óp. cit., p. 240.

${ }^{46}$ Hegel, G.W.F., Lineas fundamentales de la Filosofía del Derecho, óp. cit., parágrafo 302.

${ }^{47}$ Cf. Zan, J., La filosofía social y política de Hegel. Trabajo propiedad, óp. cit. p. 93.
} 
gobernados como de los gobernantes) no terminen por "contaminar" la universalidad y que esta última no se disuelva en la mera abstracción. Las funciones y poderes del Estado nunca pueden ser propiedad privada y aunque, inevitablemente, hayan de ser llevadas a cabo por individuos, estos lo hacen "no según su personalidad inmediata, sino solo según sus cualidades universales y objetivas" ${ }^{48}$. Lo cual no quiere decir que los cargos públicos hayan de entender su actividad como algo externo a sí mismos, al contrario: en ella han de poner "el interés principal de su existencia espiritual y particular" ${ }^{49}$. De ahí que haya de serles garantizada su subsistencia y se les exija renunciar a cualquier otro pago en la práctica de su oficio.

De acuerdo al tema que no ocupa en estas páginas, cabe detenerse sobre el importante papel que Hegel otorga las corporaciones como elemento (emergido desde la sociedad civil) mediador entre la vida civil y el Estado. Estas serían organizaciones asamblearias que acogen a los estamentos resultantes de la nueva distribución del trabajo, encargándose de comunicar al monarca las necesidades internas de las distintas esferas ${ }^{50}$. Crean, de este modo, una primera forma de consciencia de ser parte del todo, basada en los intereses comunes nacidos entre sus miembros (aunque sea aun desde la perspectiva individual y egoísta) al compartir unos modos de trabajo, una forma de satisfacción y una cultura. Ello permite que en sus representantes esté presente el interés mismo del grupo en cuestión. Desde la perspectiva opuesta (de "arriba" a "abajo"), gracias a las corporaciones los individuos resultarán cognoscibles para el monarca, "pueden ser algo para el saber racional" 51.

Hegel opta, pues, por las viejas organizaciones corporativas ${ }^{52}$ para articular la relación entre lo privado y el Estado, en detrimento de un elemento característico, y en efervescencia, del mundo moderno: la opinión pública. Si la opinión del pueblo ha tenido un papel importante en todas las épocas, el principio moderno de la libertad subjetiva, además de demandar su reconocimiento, otorga a la opinión una elevación propia: al exigir que lo que cada uno manifiesta esté justificado, esta ya no puede hacerse valer mediante la fuerza, sino apelando a la costumbre y sobre todo a la inteligencia ${ }^{53}$. La opinión constituye la gran necesidad espiritual del hombre moderno, en cuya expresión este parece hallar un placer similar al que sentían los griegos en la

\footnotetext{
${ }^{48}$ Hegel, G.W.F., Lineas fundamentales de la Filosofía del Derecho, óp. cit., parágrafo 77.

49 Ibid., parágrafo 205.

${ }^{50}$ Villacañas Berlanga, J. L., La hegemonía del pensamiento de Hegel, óp. cit. El tipo de participación de cada estamento sería acorde a las habilidades que le son propias (así, del agrícola habrá de surgir la cámara de senadores y del industrial la de diputados).

51 Hegel, G.W.F., Lineas fundamentales de la Filosofía del Derecho, óp. cit., parágrafo 310.

52 El propio Hegel parece darse cuenta de lo anacrónico de las corporaciones al hablar de su desaparición en Inglaterra o cuando apunta que "cuando en los tiempos modernos se han suprimido las corporaciones, ello tiene el sentido de que el individuo debe cuidar de sí” (Ibid., parágrafo 255).

53 Cf., Ibid., agregado, parágrafo 317.
} 
exteriorización de su bella corporeidad. "En los Estados antiguos, la finalidad subjetiva y el querer del Estado eran una sola cosa; en cambio, en los Estados modernos, exigimos una opinión propia, un querer y conciencia propios" ${ }^{54}$. Por eso Hegel defiende la libertad para exteriorizar los juicios sobre "asuntos informales" (diferente, aclara, a la "libertad de decir y escribir lo que se quiera" ${ }^{55}$ ). Pero en cualquier caso, no cabe otorgarle poder político alguno a la opinión pública: "merece ser tan apreciada como despreciada", pues en ella están vinculados lo sustancial con lo particular, recoge las creencias del fondo ético común, pero en cada una de sus expresiones particulares resulta engañosa y ilusoria" " ${ }^{6}$. Como ha observado Habermas, en su clásico estudio sobre la Öffentlichkeit, la misma constitución conflictiva, desigual y atravesada por intereses de la sociedad civil hace que Hegel (frente a Kant) no pueda ya ver en la opinión pública un principio de Ilustración y elevación a la razón ${ }^{57}$.

En definitiva, la opinión pública no es una vía correcta para mediar entre sociedad y Estado. Parece claro que en el Estado hegeliano la participación en vida política de los ciudadanos resulta bastante pobre. La democracia es una de esas cosas que quedaron sepultadas para siempre en la vieja Grecia. Lo más parecido a las discusiones del ágora se produce ahora en las deliberaciones públicas de las asambleas estamentarias, cuyos miembros son elegidos por el gobierno, para designar a sus representantes. Pero la función de esta publicidad no tiene que ver con la acogida de los pareceres provenientes del pueblo, su sentido es el inverso: que la opinión pública acceda a verdaderos pensamientos y a la comprensión de la situación y el concepto de Estado ${ }^{58}$. Al final, la contribución fundamental de los ciudadanos, además del cumplimiento general de sus deberes, parece producirse básicamente a través de los impuestos (ciertamente, una forma de mediación entre lo particular y lo universal ${ }^{59}$ ).

\section{Conclusiones}

El Mismo MOVIMIENTo HistóRICo trazado por Hegel parece oscilar entre la prevalencia de lo público y de lo privado. Así ocurría con su mirada sobre el mundo de la Antigüedad: si el espacio público de la polis griega conformaba una esfera de salida

${ }_{54}$ Hegel, G.W.F, Lineas fundamentales de la filosofia del derecho, óp. cit., agregado parágrafo 261.

55 Ibid., parágrafo 319.

${ }^{56}$ Ibid., parágrafo 316-. 318. Extraer lo verdadero que se haya enmarañado en la opinión pública y llegar a ejecutar así lo que la época quiere y expresa, es solo posible para los grandes hombres.

${ }^{57}$ Cf. . Habermas, J., Historia y crítica de la opinión pública. Barcelona, G. Gil, 1981.

${ }^{58}$ Cf. Villacañas Berlanga, J. L., La hegemonía del pensamiento de Hegel, óp. cit., p.241.

59 Gracias al carácter universal del dinero, la prestación de servicios al Estado pierde su carácter particular y arbitrario, pues permite un cómputo justo e igualitario de las prestaciones, a la vez que se respeta la libertad subjetiva para que cada cual seguir dedicándose a su actividad (Ibid., parágrafo 299). 
de lo privado -doméstico (vinculado a las necesidades naturales y al despotismo oriental), en Roma, la desaparición de lo público condujo a una reclusión en el ámbito privado, donde sin embargo, lejos de hallar libertad, las relaciones se definían por la sujeción y el interés ${ }^{60}$.

Hegel tiene claro que el suelo ético es previo al individuo y por tanto que lo público no puede ser un medio para lo privado, ni las leyes fríos vínculos artificiales. Las dependencias no son solo limitaciones sino posibilidades de realización. De modo que quien se cierra sobre lo particular, hundiéndose en el egoísmo del interés propio, no se hace independiente, $\tan$ solo obvia y amenaza esas dependencias y, con ello, a la sociedad que sostiene su existencia. Por eso la tarea del Estado no es simplemente conseguir un equilibrio entre lo público y lo privado sino conciliar ambos momentos, dando cuenta de la indeterdependencia de ambas instancias.

Si algo define la conflictiva relación moderna entre lo público y lo privado, nos enseña Hegel, es la aparición de una tercera esfera: la sociedad civil. Esta, interpuesta entre Estado e individuo, abre una escisión entre vida civil y política: los individuos salen al exterior y se relacionan unos con otros pero solo para su satisfacción particular. Si el joven Hegel había condenado este ámbito de la sociedad moderna articulado sobre la propiedad privada ${ }^{61}$, en el periodo de la Filosofía del Derecho la sociedad civil pasa a recibir una consideración positiva en virtud de su propia negatividad, como momento necesario en el movimiento dialéctico. Lo público y lo privado únicamente pueden conciliarse a través de mediaciones. Tal es el papel crucial que el trabajo pasa a ocupar en el mundo moderno, permitiendo (al menos en teoría) que nadie quede recluido en el ámbito privado y todos sean reconocidos como ciudadanos (a excepción, por supuesto, de las mujeres).

Pero, como hemos visto, la reconciliación entre las dos esferas parece chocar con ciertas dificultades que Hegel no llega a resolver. Por un lado, la última parte de la Filosofía del Derecho deja claro que el Estado ha de entenderse como organismo vivo, de manera que, para reconducir la subjetividad moderna a la unidad sustancial, Hegel pareciera no poder evitar terminar realizando una cierta vuelta a los griegos, quienes tenían el fin último de su vida puesto en la idea de Patria ${ }^{62}$. Por otro lado, en la nueva ciudad, donde el ágora es remplazada por el mercado, lo que los ciudadanos no pueden recuperar, ni así lo pretende Hegel, es el manejo de sus propios asuntos. Lo público mana básicamente de las altas instancias del Estado sin

\footnotetext{
${ }^{60}$ Como seńala Duque, en ocasiones, al hablar de Roma, Hegel pareciera estar pensando más bien en el "átomo egoísta y calculador hobbesiano, del burgués moderno" (Duque, F., Historia de la filosofia moderna: la era crítica, óp.cit, p.860).

${ }^{61}$ Cf. Zan, J., La filosofía social y politica de Hegel. Trabajo y propiedad, óp. cit., p.81 -82.

${ }^{62}$ Hegel, G.W.F., Lecciones de la filosofia de la historia, óp. cit., p.577
} 
apenas movimiento de retroalimentación desde el pueblo hacia "arriba”. Mientras, la opinión pública parece quedar reducida a una especie de señal de que la reconciliación con lo universal va por el buen camino.

Se desatan entonces las dificultades en la búsqueda hegeliana de hacer coincidir el desarrollo lógico y el curso histórico. Pues como recuerda Duque, lo que se expone en la Filosofía del Derecho es "la Idea de Estado", el Estado que corresponde a la Idea lógica (no un Estado realmente existente ni como debería ser) ${ }^{63}$. Pero la negatividad de la sociedad civil se muestra hostil a toda reintegración dialéctica.

Para adecuarse al desarrollo conceptual, Hegel parece finalmente tener que desatender a la tarea de captación de lo real. No solo porque las corporaciones estamentarias, a las que recurre para hacer de la nueva organización del trabajo una mediación entre los individuos y el Estado, fueran ya entonces instituciones en decadencia y de carácter feudal, sino también porque estas, según se desprende de las propias observaciones de Hegel, parecen incapaces de hacer nada ante las auténticas divisiones que genera el trabajo moderno: aquellas que se dan entre "clases". Tal como hemos tratado de mostrar en estas páginas, son dichas desigualdades entre las clases el obstáculo fundamental para que se realice la dialéctica entre lo público y lo privado. La pobreza, consecuencia de los egoísmos particulares que el sistema económico necesita para funcionar, imposibilita la participación espiritual en la vida pública, debido a la carencia de los medios privados de los que ahora depende el acceso a ella. En verdad, Hegel acaba encontrando una vía por la que las divisiones de clase pueden contribuir realmente a la asunción racional del cumplimiento cotidiano del deber y la adhesión del Estado. Pero esta actitud patriótica solo se alcanza a costa, por así decirlo, de su corrupción. Pues, en última instancia, son las peligrosas consecuencias y el caos que pueden resultar de las desigualdades sociales las que llevan a buscar cierta armonía en la convivencia: lo que vincula a los individuos al Estado no es ya la fuerza sino "el sentimiento fundamental del orden que todos tienen" ${ }^{64}$. Finalmente, solo el principio del orden parece capaz de articular el nuevo espacio público.

${ }_{63}$ Duque, F., Historia de la filosofía moderna: la era crítica, óp.ci., p.830

${ }^{64}$ Hegel, G.W.F., Lineas fundamentales de la Filosofia del Derecho, óp. cit., agregado parágrafo 269. 


\section{ReFERENCIAS BibLIOGRÁficas}

Barroso, Óscar, "La familia como momento de la esfera de la eticidad", El Búho, 2008, pp.89-97.

Duque, Félix, Historia de la filosofía moderna: la era critica, Madrid, Akal, 1998.

Ginzo Fernández, Arsenio, "Política, Religión y Filosofía en G.W.F. Hegel”, Revista de Estudios Políticos, N. 94, 1996, pp.111-145.

Hegel, G.W.F., Lecciones de la filosofía de la historia, Madrid, Gredos, 2010.

- Lineas fundamentales de la Filosofía del Derecho, Madrid, Gredos, 2010.

Habermas, Jürguen, Historia y crítica de la opinión pública. Barcelona, G. Gil, 1981.

Taylor, Charles, Hegel y la sociedad moderna, México D.F., FCE, 1983.

Villacañas Berlanga, José Luis, La hegemonía del pensamiento de Hegel. Voll II. La Filosofía del Idealismo alemán, Madrid, Síntesis, 2001.

Zan, Julio de, La filosofía social y política de Hegel. Trabajo y propiedad, Buenos Aires, Del Signo, 2009.

DOI: https://doi.org/10.15366/bp.2020.24.011

Bajo Palabra. II Época. No 24. Pgs: 213-228 